\title{
'Do-gooders, pink or fluffy, social workers' need not apply? An exploration of the experiences of the third sector organisations in the European Social Fund and Work Programme
}

\author{
Richard Crisp*1, Ellie Roberts ${ }^{2}$ and Dave Simmonds ${ }^{2}$ \\ ${ }^{1}$ CRESR, Sheffield Hallam University \\ 2 Centre for Economic and Social Inclusion
}

\begin{abstract}
The third sector has become increasingly reliant on contract funding from government programmes in recent years. Concerns have been expressed about this growing 'marketization' (Bruce, 2011) of the sector but relatively little is known about the experiences of third sector organisations in public service delivery, particularly in largescale programmes that use a 'prime contract' model. This paper addresses that gap by presenting evidence from two separate studies of third sector involvement in, respectively, the European Social Fund (ESF) and the Work Programme. It argues that the sector as whole, and particularly smaller providers, often find themselves 'squeezed out' at the bidding phase. Despite this, evidence from the ESF Programme shows successful subcontractors are largely positive about experiences of delivery and relationships with prime contractors, although there are concerns about excessive bureaucracy and inflexible contracts. The research also finds that the focus of largescale Programmes on hard outcomes can encourage cherry-picking and favour third sector organisations with a more 'commercial' outlook. It concludes that more could be done to promote third sector involvement in public service delivery but cautions that participating organisations may be forced to compromise social objectives.
\end{abstract}

Keywords: Third sector, European Social Fund, Work Programme, worklessness, marketization.

\section{Introduction}

There has been a growing 'marketization' (Bruce and Chew, 2011) of the third sector since the 1980s driven, in part, by increasing opportunities to compete for, and deliver, public services (see also Macmillan, 2010). This process has been marked by a shift in third sector income away from grants towards contracts. The latest UK Civil Society 
p. 77. 'Do-gooders, pink or fluffy, social workers' need not apply? An exploration of the experiences of the third sector organisations in the European Social Fund and Work Programme

Almanac (Clark et al., 2010) shows that statutory funding to the sector increased by 53 per cent over seven years from $£ 8 b n$ in 2000-01 to $£ 12.8 b n$ in 2007-08. Whilst the proportion of statutory funding received as grants has fallen from $£ 4.1$ bn in $2000-01$ to $£ 3.7 \mathrm{bn}$ in $2007-08$, contract funding increased from $£ 4 \mathrm{bn}$ to $£ 9.1 \mathrm{bn}$ over the same period. Successive governments have promoted these changes as part of a wider critique of 'grant dependency' despite the shaky empirical underpinnings of this discourse (Macmillan, 2007). The previous New Labour government also introduced two programmes, Futurebuilders and Change Up, to boost the bidding and delivery capacity of third sector organisations.

It is claimed that growing third sector involvement in service delivery has led to cultural change as some adopt the management approaches and values of the private sector (Bruce and Chew, 2011). This is seen to pose profound challenges for the sector including a 'growing risk of mission drift...and erosion of charitable values' (ibid: 156); co-option with government agendas; a loss of independence; and the prioritisation of service delivery over giving 'voice' (for debates see Macmillan, 2010; also Alcock, 2010). Research also suggests that some types of voluntary organisation have found it difficult to adapt to the changing funding landscape. Smaller organisations, for example, can struggle to meet the performance and management expectations placed on contractors (Macmillan, 2010). DWP-commissioned research on the ESF Programme also observed 'barriers to participation amongst smaller providers' in both the private and third sector' (Lloyd and Gilfillian, 2006: 39) due to factors including the risks associated with payment by outcomes and the perceived scale of bureaucracy. These concerns have prompted calls from the Charity Commission (2007: 23) for 'smaller and more local organisations to have access to appropriate capacity building opportunities'.

Despite such concerns, there is little research on the experiences of third sector organisations as subcontractors in public service delivery. This research sets out therefore to address two key gaps in understanding. Firstly, it responds to the call by the Charity Commission (2007: 23) for the '[p]otential barriers created by current frameworks for commissioning services, procurement and contracting, funding and monitoring to be fully investigated, understood and addressed'. Secondly, this paper addresses a lack of understanding the third sector experiences of subcontracting through large scale Programmes that operate a 'prime contract' model (Macmillan, 2010).

This paper reflects on these debates using evidence from two new studies. The first explores the experiences of third sector subcontractors in the European Social Fund 2007-13 Programme (Crisp et al., 2010). The second examines the bidding process for Work Programme subcontracts from the perspective of third sector organisations (Roberts and Simmonds, 2011). Drawing on this evidence the paper makes four claims. First, there is an evidence of a 'squeeze' on third sector organisations who find it difficult to secure subcontracts. Second, experiences of delivery for those who do secure subcontracts are generally, if not overwhelmingly positive. Third, third sectors feel their capacity to delivery effective services is constrained by a number of factors including administrative burdens, inflexible contracts, delays in payments and the need to meet targets. Fourth, there is evidence that the performance and management expectations can encourage 'cherry-picking' and force providers to adopt a 'commercial' approach to succeed. It concludes that more could be done to encourage the involvement of third sector organisations in delivering contracts within large-scale programmes. Nonetheless, participating organisations face the risk of compromising social objectives to meet contract specifications.

Section two which follows outlines the background to the ESF and Work Programmes as well as the research methods and objectives. Section three looks at 
p. 78. 'Do-gooders, pink or fluffy, social workers' need not apply? An exploration of the experiences of the third sector organisations in the European Social Fund and Work Programme

the extent of third sector involvement in both programmes whilst section four profiles third sector organisations involved in bidding or delivery. Section five considers experiences of bidding for subcontracts in both the ESF and Work Programmes whilst section six reviews experiences of delivering subcontracts in the ESF Programme only. Section seven concludes with reflections on how to increase third sector involvement in public service delivery.

\section{Researching the ESF and Work Programme}

This paper explores the experience of third sector organisations in bidding for or delivering contracts in the European Social Fund and the Work Programme. It draws on two separate studies:

- a survey of, and interviews with, third sector subcontractors in the ESF 2007-13 Programme presented in a recent report (Crisp et al., 2010)

- an online survey of third sector subcontractors involved in bidding for the forthcoming Work Programme (Roberts and Simmonds, 2011) plus analysis of data released by DWP on successful bidders.

Whilst there are differences in the aims, funding and architecture of both programmes (see below), they both procure providers through a prime contracting model. Prime contracts are awarded through rounds of competitive tendering to larger providers who, typically, then subcontract a number of smaller organisations including those from the third sector. This means that subcontractors' main relationship is with prime contractors rather than the Department for Work and Pensions (DWP) who oversee both Programmes. This similarity in the procurement process makes it legitimate to consider the two Programmes alongside each other.

It should be noted the research on the Work Programme only covers the bidding process whilst the ESF research includes experiences of both bidding and delivery. For this reason, only the ESF study is discussed in section six on delivery. The authors acknowledge that drawing on two separate pieces of research with different coverage sometimes complicates the narrative flow of this paper. However, we believe this is fully justified to highlight the similarities in the way the bidding system operates across both Programmes.

\section{Researching the ESF Programme}

The European Social Fund is one of the European Union's Structural Funds and is administered in England by DWP. The Programme has a dual remit of addressing worklessness and workforce skills through its two main priorities': 'Extending employment opportunities' (Priority 1) and 'Developing a skilled and adaptable workforce' (Priority 2). Funding is allocated by regional Co-Financing Organisations (CFOs) who award prime contracts through a series of competitive tendering rounds. CFOs commission either:

- prime contractors who may, in turn, recruit subcontractors to deliver elements of the prime contract

- or consortia of organisations that come together to submit a joint bid with one of these organisations nominated as a lead partner. 
p. 79. 'Do-gooders, pink or fluffy, social workers' need not apply? An exploration of the experiences of the third sector organisations in the European Social Fund and Work Programme

In 2010, the Centre for Regional Economic Social Research (CRESR) at Sheffield Hallam University was commissioned by the Third Sector European Network (TSEN) to undertake research on the experiences of third sector organisations involved in bidding for or delivering the 2007-13 ESF Programme. The research comprised two elements. First, a postal survey of 137 third sector subcontractors identified using contracts listed on the ESF website; this equates to 28 per cent of the estimated 488 subcontractors ${ }^{2}$ in the Programme. Second, telephone interviews were undertaken with 19 third sector organisations that held subcontracts or had bid unsuccessfully for subcontracts.

\section{Researching the Work Programme}

The Department of Work and Pensions (DWP) commissioned the Work Programme in 2010 for the delivery of employment support services. DWP allocated $£ 5$ bn over a five year period for the Work Programme, but funding is uncapped so has the potential to rise. The list of successful prime providers and subcontractors was announced in April 2011 and delivery will commence in June 2011 across Great Britain to eligible claimants. The key difference with the Work Programme in comparison to past programmes is that it uses a 'payment by results' model. Providers only receive the majority of their funding from DWP once they have successfully moved people into sustained employment (DWP, 2010b). DWP stated that they expected the delivery of the Work Programme to be a partnership across the public, private and third sectors ${ }^{3}$ with third sector organisations playing a role as both prime providers delivering Work Programme contracts and as subcontractors within supply chains (DWP, 2010b).

Between February and March 2010, the Centre for Economic and Social Inclusion (CESI) and Third Sector European Network (TSEN) undertook a survey of third sector organisations that had been involved in Work Programme bids. As the outcomes of bids had not been announced at the time, the survey only covered experiences of bidding including negotiations with organisations bidding to become prime providers in the Work programme. It also considered the experiences of those who decided not to express an interest in sub-contracting, and those who did but were unsuccessful in being incorporated on bids. In total 217 individuals responded to the survey from a range of organisations.

\section{The scale of third sector involvement}

Both pieces of research reflected on the extent of third sector involvement in the respective programmes. One of the aims of the survey of subcontractors in the ESF 2007-13 Programme was to identify the proportion of ESF allocated to the third sector. Estimates based on survey returns suggest there are approximately 488 unique subcontractors who hold subcontracts worth a total value of $£ 134.6$ million. This only equates to 4 per cent of the estimated $£ 3.4$ billion $^{4}$ awarded through ESF 2007-13 so far. However, it is important to exercise caution in interpreting these figures. The total value of prime contracts ( $£ 3.4$ billion) is not equal to the total value of all subcontracts as prime contractors will take some of this in the form of a management fee. For this reason, the figure of 4 per cent potentially underestimates allocations to the third sector.

The previous evidence review of the 'Impact of the ESF' (Crisp et al., 2009) found a similar pattern at prime contracting level. Analysis of publicly available data on the size of prime contracts on the ESF website found that the third sector only receives 17.7 per cent of the total value of prime contracts. This was less half that awarded to the public sector (35.2 per cent) and the private sector (41.1 per cent). As Table 1 below shows, the larger share of ESF funding awarded to the private sector is explained by its 
p. 80. 'Do-gooders, pink or fluffy, social workers' need not apply? An exploration of the experiences of the third sector organisations in the European Social Fund and Work Programme

tendency to secure larger than average contracts (almost a third larger than the overall ESF average). Third Sector organisations are, by comparison, involved in smaller than average initiatives. It would appear, therefore, that the sector plays a limited role at both prime and subcontracting tiers.

Table 1: ESF Prime Contractors: Average Size of Projects by Sector $(£)$

\begin{tabular}{lrrrrr}
\hline & Not for Profit & Private & Public & Third & All \\
\hline ENGLAND & $£ 1,752,181$ & $£ 1,276,658$ & $£ 886,280$ & $£ 680,357$ & $£ 985,237$ \\
$\%$ of national average & 177.8 & 129.5 & 90.0 & 69.1 & 100 \\
\hline Source: (Crisp et al., 2009) & & & & &
\end{tabular}

Similar data on the value of contracts in the Work Programme is not available as payment is will be based on future results. However, it is possible to analyse the number of contracts awarded. DWP announced their preferred bidders in April 2011 (DWP, 2011). Thirty seven primes providers across 18 Contract Package Areas (CPAs), including 2 voluntary sector primes (Careers Development Group and Rehab Group) were awarded contracts to deliver the Work Programme in partnership with their supply chains. The results ${ }^{5}$ are detailed in Table 2 below which shows the proportion of total contract volumes that will be self-delivered or subcontracted by sector. In total the voluntary sector will deliver 19.4 per cent of the Work Programme. This comprises 1.1 per cent self-delivered by prime providers and 18.3 per cent delivered as subcontractors. By comparison, the private sector will deliver 72 per cent (42 per cent self-delivered and 30 per cent as subcontractors) and the public sector 8.6 per cent entirely as subcontractors.

Table 2: Percentage of total volume of contracts in the Work Programme delivered by sector $(2011 / 12)$

\begin{tabular}{lrrrr}
\hline $\begin{array}{l}\text { Sector of prime } \\
\text { provider }\end{array}$ & $\begin{array}{r}\text { Self delivered by } \\
\text { prime (\%) }\end{array}$ & $\begin{array}{r}\text { Voluntary sub } \\
\text { contract (\%) }\end{array}$ & $\begin{array}{r}\text { Public sub } \\
\text { contract (\%) }\end{array}$ & $\begin{array}{r}\text { Private } \\
\text { subcontract (\%) }\end{array}$ \\
\hline Private & 42.0 & 16.2 & 7.1 & 24.5 \\
Public & 0.0 & 0.5 & 1.1 & 2.0 \\
Voluntary & 1.1 & 1.6 & 0.4 & 3.5 \\
Total subcontracts & N/A & 18.3 & 8.6 & 30 \\
\hline
\end{tabular}

Although the private sector undoubtedly won the majority of Work Programme delivery, the voluntary sector was not wholly overlooked. Inclusion's financial model shows these results will equate to $£ 86 \mathrm{~m}$ per year for the voluntary sector. There is, however, little doubt that overall the voluntary sector has been squeezed out relative to other sectors. This means there will be a limited role for voluntary organisations in tackling worklessness as part of the Work Programme. A clear pattern emerges from both studies, therefore, of third sector organisations failing to command significant allocations of Programme funding as measured by value or number of contracts. The prime contracting model appears to disadvantage the sector in competition for contracts, particularly when compared to outcomes for the private sector. 
p. 81. 'Do-gooders, pink or fluffy, social workers' need not apply? An exploration of the experiences of the third sector organisations in the European Social Fund and Work Programme

\section{The profile of third sector organisations}

Data from both studies provides an insight into the type of third sector organisations that bid for or secure contracts. The survey of third sector subcontractors in the ESF found that a large proportion of respondents were from large or very large organisations as Table 2 below indicates:

Table 3: Organisation size by income band

\begin{tabular}{llll}
\hline & & N & Per cent \\
\hline Small & Less than $£ 250 K$ & 26 & 20 \\
Small-medium & $£ 250 \mathrm{~K}$ to $£ 499 \mathrm{~K}$ & 21 & 16 \\
Medium-large & $£ 500 \mathrm{~K}$ to $£ 999 \mathrm{~K}$ & 23 & 17 \\
Large & $£ 1 \mathrm{~m}$ to $£ 2.49 \mathrm{~m}$ & 37 & 28 \\
Very large & More than $£ 2.5 \mathrm{~m}$ & 26 & 20 \\
\hline Base=133 & & &
\end{tabular}

Nearly half of responses (48 per cent) were from large or very large organisations while only one-fifth (20 per cent) were from small organisations. These findings about the size of organisations with ESF subcontract are in stark contrast to what is known about the wider population of third sector organisations. Large or very large organisations only make-up 2.7 per cent of third sector organisations in the UK (Clark et al., 2010). Such findings could be a concern for practitioners and policymakers alike as the third sector, including smaller organisations, are often recognised as having particular expertise in engaging 'harder-to-reach groups (e.g. House of Lords European Committee, 2010). Any squeeze on the involvement of the third sector could compromise the ability of the Programme to realise its objective of supporting 'people who are at a disadvantage in the labour market, including those who experience multiple disadvantages' (DWP/DIUS, 2007: 12).

Similar findings emerge from the Work Programme survey which measures organisational size by the number of workless people supported. This also found that a large proportion of respondents were from large organisations as Table 4 below indicates:

Table 4: Number of workless people supported over 12 month period

\begin{tabular}{lll}
\hline & N & Per cent \\
\hline Under 10 & 6 & 3 \\
10 to 50 & 17 & 9 \\
$51-100$ & 25 & 13 \\
$101-250$ & 48 & 24 \\
$251-500$ & 28 & 14 \\
$500+$ & 73 & 37 \\
\hline Base=197 & &
\end{tabular}

Fifty-one per cent of respondents to the survey had supported more than 250 workless people over the past 12 months, with 37 per cent having supported more than 500. Of those included in bids, large organisations (supporting over 250 workless people) represented 84 per cent. In comparison, just over half (57 per cent) of the smaller organisations that were surveyed were successful in being included in bids, 
p. 82. 'Do-gooders, pink or fluffy, social workers' need not apply? An exploration of the experiences of the third sector organisations in the European Social Fund and Work Programme

with 43 per cent of the smaller organisations stating that they had not been included. This indicates that larger organisations were more successful in their subcontracting negotiations, and that smaller organisations significantly lost out in this process. Summarising across both studies, therefore, the third sector may be squeezed out of $n$ the ESF and Work Programmes compared with other sectors. Nonetheless, when it does gain a foothold, it is disproportionately the larger third sector providers that are successful.

\section{Experiences of bidding for ESF and Work Programme contracts}

Looking firstly at the ESF Programme, both the survey and interview data highlighted a number of concerns about the process of bidding. Dissatisfaction centred on the volume and complexity of paperwork involved as well as inadequate feedback on successful bids. The survey found that a majority of subcontractors (53 per cent) felt the process was 'overly bureaucratic'. This figure rose to 77 per cent for 'unsuccessful' or 'discouraged' applicants, suggesting that excessive bureaucracy may be seen as a factor contributing to failed bids. Interviews with a small number of unsuccessful applicants also identified other explanations for a lack of success. One organisation was disqualified on the basis of being too small relative to contract value. Two others were, respectively, not informed of outcomes or subsequently not awarded work by prime contractors despite being included on successful bids. Whilst this group is too small to reflect conclusively on the reasons why third sector organisations sometimes struggle to access to ESF, it does indicate that size may be an issue.

All organisations with ESF subcontracts were asked to reflect on why bids were successful. By far the most commonly cited factor was a track record of successful delivery of ESF or other contracts. One implication is that this could disadvantage firsttime applicants who cannot demonstrate past experience of delivering ESF. Indeed, the survey also found that 45 per cent of all respondents and 69 per cent of 'discouraged' or 'unsuccessful' bidders felt that the application process placed new applicants at a disadvantage.

Turning to the Work Programme, the survey provides an even greater level of detail on the experiences of third sector organisations. Nearly one third of all respondents were not included in any Work Programme bid, of which 43 per cent were small organisations. As with the ESF Programme, there were concerns about bidding procedures. Most respondents felt the bidding process was over complicated and overwhelmingly reported a lack of understanding or awareness of the bidding process which prohibited or limited them from participating. Many felt they could have been given more information and guidance in the initial stages of the processes to aid their understanding of the programme and how they could be involved. These difficulties may reflect the lack of capacity within smaller third sector organisations to fulfil complex and demanding requirements for bidding for subcontracts through large-scale Programmes. It would support the Charity Commission's (2007: 23) assertion of the need for 'smaller and more local organisations to have access to appropriate capacity building opportunities'.

The majority of respondents not included on bids did express an interest but most were turned down by organisations leading the bid. Moreover, the process lacked transparency. Of those turned down, 83 per cent felt that they had not been given an adequate explanation as to why this had been the case. A failure to get accepted in bids could also impact negatively on future delivery. Half of organisations not included on bids reported that they were likely to cease operating services to workless people. However, some did turn down offers of being included in bids, mostly because the 
p. 83. 'Do-gooders, pink or fluffy, social workers' need not apply? An exploration of the experiences of the third sector organisations in the European Social Fund and Work Programme

financial terms were not good enough. Again this is a particularly important issue for the smaller organisations with less financial capacity.

For those who were successfully included in Work Programme bids, over 50 per cent were included in five or more bids. It is likely these organisations had a greater capacity to manage and plan their involvement in the Work Programme bidding process. Although 43 per cent felt that they had been afforded some leeway with their financial negotiations with those leading bids, most felt that they had been given no choice in this matter. It remains to be seen if voluntary sector organisations will be able to operate under conditions where finances have been dictated from higher up in the supply chain without any flexibilities. There were strong feelings that the financial risks that sub-contractors were taking on were high, and this needs to be managed carefully as delivery of the Work Programme starts. As the following section shows, such concerns are borne out by the experiences of third sector subcontractors in the ESF.

On balance, this section shows that there are considerable concerns across both Programmes about the ability of third sector organisations to bid for, and secure, contracts. The bidding process was widely perceived as complex and lacking in transparency. It also seemed to disadvantage smaller third sector organisations in particular. That these similarities hold across both programmes suggest it is the prime model per se rather the unique dynamics of any single Programme that creates these difficulties.

\section{Experiences of delivering subcontracts in the ESF Programme}

The survey asked third sector organisations about their overall levels of satisfaction with their experience as a subcontractor in the ESF 2007-13 Programme. They were generally, if not overwhelmingly, positive with 63 per cent of respondents describing themselves as satisfied and 20 per cent dissatisfied. A majority of survey respondents also felt subcontracts enabled them to draw on organisational strengths (76 per cent), work with disadvantaged clients (66 per cent) and deliver a high quality service (66 per cent). These findings were corroborated by interviews which found that that, on the whole, subcontractors felt that the Programme enabled them to address a genuine need and to support individuals that might not otherwise have received this assistance. This indicates that whilst the third sector may experience difficulties in accessing ESF funds, as shown above, they are largely positive about experiences once in the Programme. Survey respondents were also largely positive about relationships with prime contractors. A majority felt there were clear lines of communication with the prime contractor (75 per cent), that the prime contractor provided appropriate support and guidance (64 per cent) and that they had a good relationship with the individual from the prime contractor with responsibility for managing the sub-contract (79 per cent).

\section{Factors constraining delivery}

Whilst overall experiences were generally positive, interviews with third sector subcontractors identified several factors that constrained delivery. These broadly fell into four categories relating to administrative burdens, inflexible contracts, delays in payments and the need to meet targets. Taking each in turn, some subcontractors expressed frustration at the excessive volume of paperwork they had to complete to enroll clients or record outcomes. Typical descriptions include that it 'gave us huge headaches', 'was ridiculous' or proved the 'main difficulty' in delivering the service. 
p. 84. 'Do-gooders, pink or fluffy, social workers' need not apply? An exploration of the experiences of the third sector organisations in the European Social Fund and Work Programme

A second concern was the lack of flexibility within contracts with frustrations voiced about restrictive eligibility criteria, overly prescriptive delivery requirements or insufficient contract length. For example, one medium-sized third sector organisation with three ESF contracts to provide ESOL, skills development and employment support identified a number of inflexibilities in their subcontract. Firstly, they felt the 30 hour limit placed on working with individuals not in employment, education or Training (NEETs) was insufficient to meet the intensive needs of clients. Secondly, the tightly prescribed pathways for individuals engaged on the NEETs project meant there was 'very, very little flexibility'. The subcontract specified that the 14-16 year-old group could only be assisted into further education whilst the 16-19 year-old group had to be placed in employment. There was no 'crossover' which meant, for example, that a 17 year-old helped to enroll at college would not be funded through the ESF contract.

A third concern related to payments with many subcontractors reporting difficulties such as delays in prime contractors signing off reported outcomes or end-loading where most funding was awarded on the basis of final outcomes. The concern about end-loading was also echoed by the survey which found that 44 per cent of subcontractors felt that the timing of the subcontract payments placed a disproportionate amount of risk on their organisation.

One implication of these findings is that smaller organisations that do not have access to other income streams or reserves may experience difficulties in accommodating delays or payment structures. This has particular resonance for the Work Programme where a 'payment by results' model means prime contractors are expected to self-finance upfront delivery with DWP payments only made for outcomes achieved. Prime contractors have the choice about how they finance sub-contractors but for the large 'end-to-end' sub-contracts it is likely that primes will offer the same terms as DWP. However, smaller and specialist 'call off' contracts could have less emphasis on outcome payments. If this end-loading filters down to subcontractors, it could preclude the participation of third sector organisations unable to draw on other income streams.

A fourth and final concern related to the negative impact of targets on capacity to engage the hard-to-reach. Whilst survey findings reported above showed that two thirds of subcontractors felt able to work with disadvantaged clients, interviews did find evidence of 'cherry-picking'. This included one provider subcontracted to engage marginalised groups such as the homeless and young offenders in basic skills courses. They described how they struggled to meet targets because referrals had come through 'difficult agencies' including bail hostels and other parts of the Criminal Justice System. This has discouraged them from recruiting through these routes in the future: 'Would we go for the most in need in the future? We would be wary of it and that's not ideal as we work with the hard-to-reach'. One implication of such cherry-picking is that could compromise the Programme objective of supporting 'people who are at a disadvantage in the labour market, including those who experience multiple disadvantages' (DWP/DIUS (2007: p12).

A further consequence of targets identified by one larger subcontractor is the need to concentrate on hard outcomes and adopt a business-like approach. They suggested it was important that staff were outcome focused rather than 'do-gooders, pink or fluffy, social workers'. Another provider also highlighted the importance of being what one called 'reasonably commercial'. Indeed, one third sector subcontractor interviewed that worked with a private sector prime organisation observed that: 'they are very good, very efficient, very professional. We can learn a lot from them'. Whilst these were not majority views, they nonetheless underline how performance pressures can encourage a commercial approach in line with concerns about "marketization' outlined by Bruce and Chew (2011). 
p. 85. 'Do-gooders, pink or fluffy, social workers' need not apply? An exploration of the experiences of the third sector organisations in the European Social Fund and Work Programme

\section{Conclusions}

A clear narrative emerges findings from both studies research on the experience of third subcontractors. There is evidence that the sector as a whole, and particularly smaller organisations within the sector, are being 'squeezed out' at both the bidding and delivery phase. Despite this squeeze, third sector organisations delivering subcontracts are largely positive about their experience of involvement in the ESF Programme. They generally believe they deliver a valuable service that addresses the needs of disadvantaged client groups. The Programme is not an unqualified success however. There are recurrent and often severe criticisms of the way the bidding and delivery process operates. Many subcontractors feel that excessive levels of bureaucracy, inflexible contracts or targets constrain their ability to deliver the highest quality service possible.

These findings have four key implications for the way subcontractors are commissioned as providers within national programmes to tackle worklessness and raise skills. First, the evidence of the squeeze on third sector involvement challenges the claims made by policymakers about the need to involve the Third Sector in the delivery of national programmes. For example, it undermines the position outlined by the Minister for Employment, Chris Grayling, in a letter ${ }^{6}$ to potential contractors:

We have been very clear to all of the organisations on the framework that they must demonstrate their ability to address the specific needs and barriers of each customer in every locality. In order to do so, they will need to engage with a range of smaller local and specialist organisations including those from the voluntary sector.

This paper suggests this aim remains aspirational and is unlikely to be achieved without providing additional support to enable third sector organisations to compete for public sector contracts. This could include capacity building to bolster organisational capabilities. This echoes the Charity Commission's (2007: 23) call for 'smaller and more local organisations to have access to appropriate capacity building opportunities'.

However, this is no guarantee capacity building will improve prospects for the third sector. The tendency towards issuing larger prime contracts to a smaller number of providers, as in the Work Programme, may militate against the success of any capacity building initiatives. If the scale of prime contracts translates into larger subcontracts, the tendency for smaller providers to be 'squeezed out' may only accelerate. Moreover, capacity building may have little impact if, as some critics claim ${ }^{7}$, the move towards privatising welfare delivery is politically motivated. At the very least, there is an apparent disregard for evidence that Jobcentre Plus can perform equally effectively as the private sector in delivering welfare-to-work Programmes (National Audit Office, 2010).

Second, prime contractors could do more to ease or remove the constraints that hinder the capacity of third sector organisations to deliver services. Two key points can be made here. First, they should reduce the burden of paperwork by ensuring efficient, consistent and transparent administrative systems in place from the outset. Second, they need to minimise financial risk by processing claims efficiently and sequencing payments to avoid excessive end-loading that causes problems for smaller organisations most vulnerable to cash flow problems. As noted, however, this could be problematic in the Work Programme if prime providers pass on their DWP payment terms to subcontractors given that payments are primarily paid on the basis of successful and sustained outcomes. 
p. 86. 'Do-gooders, pink or fluffy, social workers' need not apply? An exploration of the experiences of the third sector organisations in the European Social Fund and Work Programme

Third, those third sector organisations that want to secure subcontracts may need to be, in the words of one subcontractor, 'reasonably commercial'. This means having the processes and systems in place to manage contracts effectively combined with a strong focus on achieving hard outcomes. Evidently, the challenge is how this can be done without losing sight of social aims or engaging in cherry-picking that sidelines disadvantaged clients. The high performance expectations of the Work Programme will only intensify the pressures faced by subcontractors in the ESF programme already identified in this paper. The claim by one provider that there is no room for 'do-gooders [or] pink or fluffy, social workers' is controversial but does capture the tensions inherent in operating this kind of funding environment.

Such findings appear to confirm concerns about the 'growing risk of mission drift...and erosion of charitable values' (Bruce and Chew, 2011: 156). Whilst third sector organisations are clearly not sidelining social objectives altogether, there is some evidence that a commercial approach and, at times, cherry-picking are necessary to hit targets. At the same time, this must be balanced against survey findings that two thirds of third sector organisations subcontracted through the ESF feel able to work with disadvantaged clients. It is important not to overstate the extent to which 'marketization' is forcing a fundamental rebalancing of priorities in the sector.

Fourth, the third sector as a whole could do more to construct an evidence-based case as to why it should receive a larger proportion of available funding relative to other sectors. There is little reliable data or research from the ESF Programme (see Crisp et al., 20098) or elsewhere (see Macmillan, 2010) that the third sector has a natural advantage over its public or private counterparts in engaging and supporting more marginal groups to find work. This may well be a particular strength of the sector but, as it stands, the sector lacks substantive research or performance analysis to demonstrate this compellingly. Providing evidence of a unique capacity to deliver projects to tackle worklessness or raise skills would surely bolster the argument that more should be done to facilitate third sector involvement.

\section{Notes}

1 Priorities 1 and 2 apply to all English regions except Cornwall and the Isles of Scilly which has its own priorities - Priorities 4 and 5 - as a 'Convergence area' that, unlike the other English regions, has a regional GVA less than 75 per cent of the European average. Priorities 4 and 5 effectively mirror Priorities 1 and 2, however, with the dual focus on employment and skills. For a full list of priorities and explanation of the architecture of the Programme, see DWP/DIUS (2007: p12) England and Gibraltar European Social Fund Convergence and Competitiveness and Employment Programme 2007-13. London: TSO.

2 For the calculations on which this estimate is derived see Crisp et al. (2010: 12).

3 Taken from the DWP website: http://www.dwp.gov.uk/supplying-dwp/what-webuy/welfare-to-work-services/work-programme/ on 09/05/2011.

4 The $£ 3.4$ billion figure is the sum of all prime contracts listed on the ESF website (http://www.dwp.gov.uk/esf/) and includes public sector match funding provided through programmes such as Flexible New Deal. An alternative lower figure might be $£ 2.31 \mathrm{bn}$. This is the total sum of Regional Co-Financing Beneficiary Agreements 200710 (ESF plus public match) published on the ESFD website. Using this figure increases third sector subcontractor's share of ESF to 5.8 per cent.

${ }^{5}$ Results have been analysed by the Centre for Economic and Social Inclusion. Source: DWP Work Programme results and a letter from the Minister of Employment, dated April 2011, sourced from www.socialenterpriselive.com (percentages are based on DWP's assessments of Work Programme bids, and will be subject to change). 
p. 87. 'Do-gooders, pink or fluffy, social workers' need not apply? An exploration of the experiences of the third sector organisations in the European Social Fund and Work Programme

6 Cf. Grayling on the voluntary sector and the work programme [online], available at http://www.carleyconsult.com/2010/12/10/353/ accessed 10 March 2011.

7 See for example a statement from the Public Services and Commercial Union: http://www.pcs.org.uk/en/news and events/news centre/index.cfm/id/4E32C3DF-

EB6E-447C-94C228BA479E98DD [accessed June 2011].

8 This is set to change with a forthcoming piece of research by the LSC that looks at the role of the Third Sector in delivering ESF as part of a broader evaluation of the involvement of the sector in delivering LSC-funded provision through FE, Work-Based Learning or ESF. The research is not due to be published though until November 2009. Otherwise, little sectoral analysis of this kind seems to exist. Correspondence with the Research and Programme Monitoring teams at DWP revealed that data on performance by sector was never systematically captured or analysed for the Objective 3 programme.

\section{Acknowledgements}

The authors would like to thank Sandra Turner and Jamie Thoroughgood from the Third Sector European Network (TSEN) for their help in undertaking the research. We are also grateful to colleagues involved in the two studies and to those who participated in the research. Thanks are also due to the referee for helpful comments on the paper. The findings and conclusions presented however remain the responsibility of the authors.

* Correspondence Address: Richard Crisp, CRESR, Sheffield Hallam University, Unit 10 Science Park, Howard Street, Sheffield, S1 1WB. Email: r.crisp@shu.ac.uk.

\section{References}

Alcock, P. (2010) Building the Big Society: a new policy environment for the third sector in England. Voluntary Sector Review, 1, 3, 379-89.

Bruce, I. and Chew, C. (2011) Debate: The marketization of the voluntary sector. Public Money and Management, 31, 3, 155-157.

The Charity Commission (2007) Stand and deliver: The future for charities delivering public services. Liverpool: Charity Commission.

Clark, J., Kane, D., Wilding, K., Wilton, J. (2010) The UK Civil Society Almanac. London: NCVO.

Crisp, R., Gore, T. and Wells, P. (2009) Evidence review of the impact of the ESF on those furthest from the labour market. London: TSEN.

Crisp, R., Dayson, C., Pearson, S. and Wilson, I. (2010) The experience of third sector subcontractors in the European Social Fund 2007-13 Programme. London: TSEN.

DWP/DIUS (2007) England and Gibraltar European Social Fund Convergence and Competitiveness and Employment Programme 2007-13. London: TSO.

DWP (2010a) Work Programme Prospectus. London: DWP.

DWP (2010b) Work Programme ITT, version 5. London: DWP.

DWP (2011) Work Programme preferred Bidders. London: DWP.

HM Treasury (2010) Spending Review 2010. London: Stationary Office.

House of Lords European Union Committee (2010) Making it Work: the European Social Fund, Volume 1: Report. London: The Stationery Office.

Lloyd, R. and Gilfillian, C. (2006) Third evaluation of European Social Fund co-financing in England. London: DWP. 
p. 88. 'Do-gooders, pink or fluffy, social workers' need not apply? An exploration of the experiences of the third sector organisations in the European Social Fund and Work Programme

Macmillan, R. (2007) Understanding the idea of 'grant dependency' in the voluntary and community sector. People, Place \& Policy Online, 1, 1, 30-38.

Macmillan, R. (2010) The third sector delivering public services: an evidence review, Working Paper 20, July 2010. Birmingham: TSRC.

National Audit Office (2010) Support to incapacity benefits claimants through Pathways to Work. London: TSO.

Roberts, E. and Simmonds, D. (2011) Voluntary Sector Involvement in the Work Programme. London, Centre for Economic and Social Inclusion.

TSEN (2010) TSEN (Third Sector European Network) response to Lords Inquiry. TSEN [available online at: http://www.tsen.org.uk/docutsenpublications.asp, accessed 21 April 2011]. 